\title{
Alkaloid Quantities in Endophyte-Infected Tall Fescue are Affected by the Plant-Fungus Combination and Environment
}

\author{
M. Helander ${ }^{1,4}$ - T. Phillips ${ }^{2}$ - S. H. Faeth ${ }^{3}$ L. P. Bush ${ }^{2}$ - R. McCulley ${ }^{2}$ I. Saloniemi ${ }^{1}$ • \\ K. Saikkonen ${ }^{4}$
}

Received: 20 August 2015 / Revised: 10 January 2016 / Accepted: 15 January 2016 /Published online: 27 January 2016

(C) The Author(s) 2016. This article is published with open access at Springerlink.com

\begin{abstract}
Many grass species are symbiotic with systemic, vertically-transmitted, asymptomatic Epichloë endophytic fungi. These fungi often produce alkaloids that defend the host against herbivores. We studied how environmental variables affect alkaloids in endophyte-infected tall fescue (Schedonorus phoenix) from three Northern European wild origins and the widely planted US cultivar 'Kentucky-31' (KY31). The plants were grown in identical common garden experiments in Finland and Kentucky for two growing seasons. Plants were left as controls (C) or given water (W), nutrient $(\mathrm{N})$ or water and nutrient $(\mathrm{WN})$ treatments. For 8 10 replications of each plant origin and treatment combination in both experiments, we analyzed ergot alkaloids, lysergic acid, and lolines. In Finland, tall fescue plants produced $50 \%$ more ergot alkaloids compared to plants of the same origin and treatments in Kentucky. Origin of the plants affected the ergot alkaloid concentration at both study sites: the wild origin plants produced 2-4 times more ergot alkaloids than KY31, but the ergot alkaloid concentration of KY31 plants was the same at both locations. Overall lysergic acid content was $60 \%$ higher in plants grown in Kentucky than in those grown in Finland. Nutrient treatments $(\mathrm{N}, \mathrm{WN})$ significantly
\end{abstract}

M. Helander

helander@utu.fi

1 Department of Biology, University of Turku, 20014 Turku, Finland

2 Department of Plant and Soil Sciences, University of Kentucky, Lexington, KY 40546-0312, USA

3 Department of Biology, University of North Carolina, Greensboro, NC 27402-6170, USA

4 Natural Resources and Biomass Production Research, Natural Resources Institute Finland (Luke), 20520 Turku, Finland increased ergot alkaloid concentrations in plants from Finland but not in plants from Kentucky. These results suggest that the success of KY31 in US is not due to selection for high ergot alkaloid production but rather other traits associated with the endophyte. In addition, the environmental effects causing variation in alkaloid production of grass-endophyte combinations should be taken into account when using endophyte-infected grasses agriculturally.

Keywords Ergot alkaloids · Fungal endophytes · Grasses · Lolines $\cdot$ Lysergic acid $\cdot$ Nutrients $\cdot$ Water

\section{Introduction}

Grasses (Poaceae) have invaded every continent of the globe, and cover more terrestrial area than any other group of plants. Temperate grasses of the subfamily Pooideae are integral components of natural grassland ecosystems. These grasses also are economically important crop plants that are cultivated in monocultures and polycultures, mainly as animal forage to help feed the globe's growing population.

The majority of grass species in pastures and natural grasslands are perennials, capable of tolerating high grazing pressure from vertebrate herbivores. This tolerance is based mainly on their rapid regrowth capacity, their underground storage organs, and their ability to grow new tillers following defoliation (Dyer et al. 1991; Karban and Baldwin 2007). The dominance of grassland ecosystems across all the continents except Antarctica indicates that grasses are competitive across a range of abiotic conditions. Yet grasses, despite high levels of herbivory, appear to invest little in chemical defense compared to other plants. Grasses typically have high levels of silicon (Si) phytoliths in leaf and other above ground parts, and these are thought to provide physical defense against herbivory 
(Huitu et al. 2014; Rudall et al. 2014; Vicari and Bazely 1993). The ability of grasses to produce secondary chemical defense compounds such as alkaloids is limited (Huitu et al. 2014; Vicari and Bazely 1993).

Instead of producing chemical compounds themselves, many pooid grasses have coevolved with vertically-transmitted, symbiotic Epichloë fungi (Saikkonen et al. 2013; Schardl et al. 2013) whose asexual forms formerly were referred to as Neotyphodium (Leuchtmann et al. 2014). These hereditary symbioses are typically host specific. The fungi grow in intercellular spaces in the above-ground parts of grasses. Epichloë endophytes in their host grasses are capable of producing four classes of alkaloids, which may provde the endophyte-grass symbiota with defenses against herbivores. The ergot alkaloids (e.g., ergovaline) and indole-diterpenes (e.g., lolitrem B) are active against both vertebrate and invertebrate herbivores, whereas peramine and loline alkaloids specifically affect invertebrate herbivores (Schardl et al. 2013).

Tall fescue [Schedonorus phoenix (Scop.) Holub. ex. Lolium arundinaceum (Schreb.) S. J. Darbyshire, syn. Festuca arundinacea Schreb.] is an important agronomic cool-season grass with a world-wide distribution. This grass often hosts the systemic endophytic fungus, Epichloë coenophiala (Morgan-Jones \& W. Gams) C.W. Bacon \& Schardl [formerly Neotyphodium coenophialum (MorganJones \& W. Gams) Glenn, C.W. Bacon \& Hanlin]. Tall fescue originated in Eurasia, where it can be found growing in low competition environments, such as roadsides and seashores. The species was introduced to US in the late 1800's, and today is a widely distributed and important forage and turf grass in the eastern and middle United States and is less widely distributed in South America, New Zealand, and Australia (Hoveland 1993; Young et al. 2014).

'Kentucky-31' (KY31) was the first widely used tall fescue cultivar in the US (Young et al. 2014). Empirical evidence has demonstrated that the systemic and asymptomatic endophytic fungus made the cultivar particularly vigorous, highly resistant to herbivores, and tolerant to a wide range of environmental conditions (Clay and Holah 1999; Saikkonen 2000). The endophyte thus has promoted competitive dominance of infected grasses especially in stressful environments (Malinowski and Belesky 2000; Saikkonen et al. 2004, 2006).

It also is well documented that the Epichloe endophyteinfected KY31 tall fescue can cause health problems for grazing vertebrates, especially during long and hot summers (Bacon 1995; Young et al. 2013). Consumption of endophyte-produced alkaloids has been implicated directly in the onset of animal stress, specifically in the case of the ergot alkaloids (Foote et al. 2013; Young et al. 2013). Significant scientific effort has been spent trying to unravel the mechanisms associated with this animal response. Surprisingly, less attention has been paid to the variation in alkaloid production of the grass-endophyte symbiota caused by variable environmental conditions and to how alkaloidenvironment relationships may be influenced by the genetic background of the host grass.

We examined how alkaloid production in wild tall fescues originating from Northern Europe, which are highly infected with Epichloë endophytes (ca. 90 \%, Saari et al. 2010), and the widely used US cultivar KY31 depends on variable environmental conditions. Endophyte-infected wild grasses from three different origins around the Baltic Sea and the cultivar KY31 were planted in identical common garden experiments in two environments, Northern Europe and Kentucky, where soil nutrients and water were manipulated. We expected the cultivar KY31 to produce high levels of alkaloids, especially in high nutrient environments (Arechavalenta et al. 1992) that mimic the agronomic-type environment. Nutrient application should increase the production of fungal alkaloids because alkaloids are nitrogen-rich compounds and nitrogen is often limiting in the environment. We also predicted that overall alkaloid production would be lower in Northern Europe than in Kentucky since in the latter environment the grasses would be exposed to higher temperatures and drought during the summers (Belesky et al. 1989; McCulley et al. 2014).

\section{Methods and Materials}

Plant Material Seeds from naturally occurring, wild tall fescue populations from three areas that were separated approx. $500 \mathrm{~km}$ from each other by the Baltic Sea were collected in August 2003. We collected seeds from 8, 9, and 6 populations, respectively, from the island of Åland (A), the island of Gotland (G), and the West Coast of Sweden (S), 10-50 individual plants from each population. Three seeds from each individual plant were stained (Saha et al. 1988), and endophyte infections were determined by microscopic examination. All the tall fescue populations in the study had seed borne Epichloë sp., and infection frequencies varied between 85 and $100 \%$. We combined all E- (uninfected) seeds from populations within each area (A, G, and S) and all $\mathrm{E}+$ (infected) seeds from populations within each area. In addition to plants from these natural tall fescue populations, both infected and uninfected 'Kentuky-31' (KY31) cultivar seeds were obtained from the University of Kentucky. Half of all the seeds were shipped from Finland to Kentucky or vice versa, so that both study sites had identical sets of seeds. At both locations, tall fescue seeds were germinated on moist tissue paper in Petridishes and planted in individual pots in a greenhouse. When plants had 2-3 tillers, they were transplanted to field plots.

Common Garden Experiments Parallel field experiments were carried out in the fields of Turku Botanical Garden, University of Turku $\left(60^{\circ} 26^{\prime} 0^{\prime \prime} \mathrm{N}, 22^{\circ} 10^{\prime} 19^{\prime \prime} \mathrm{E}\right)$, Finland and the University of Kentucky‘s experimental Eden Shale Farm 
$\left(38^{\circ} 32^{\prime} 22^{\prime \prime} \mathrm{N}, 8^{\circ} 44^{\prime} 24^{\prime \prime} \mathrm{W}\right)$, Kentucky, USA. The field site in Finland is at the edge of the northern distribution range of natural tall fescue populations, while the Kentucky field site is in the zone of intensive tall fescue cultivation in the USA, also known as the 'fescue belt'. Both experimental field sites had been in cultivation in the past and were tilled without nutrient application in the summer 2004, immediately preceding experimental establishment. The experimental areas were fenced to prevent large vertebrates (e.g., rabbits, deer) access; however, smaller vertebrates (e.g., voles) and invertebrates were able to move freely into the experimental area and among plants.

In the control plots, $\mathrm{pH}$ of the experimental soils were 6.7 and 5.9, total nitrogen $0.15 \%$ and $0.14 \%$, phosphorus 7 and $14 \mathrm{mg} / \mathrm{kg}$, potassium 132 and $81 \mathrm{mg}$, calcium 1800 and $2080 \mathrm{mg} / \mathrm{kg}$, and magnesium 208 and $120 \mathrm{mg} / \mathrm{kg}$ for Finland and Kentucky sites, respectively.

Both experimental set-ups were randomized block designs consisting of 10 blocks, each divided to 4 plots. In August 2004, E+ plants from four origins (A, G, S, KY31) were randomly planted in each experimental plot about $0.5 \mathrm{~m}$ apart and $0.5 \mathrm{~m}$ from the edge of the plot. The space between the experimental plants was either mowed, hand weeded, or sprayed with herbicide two times during the growing season to prevent interspecific competition. E- plants of the same origin also were planted in the plots, but were not included in this study, because uninfected plants are not capable of producing alkaloids.

The four plots in each block were designated randomly to one of the four treatments: Control (C) - receiving only ambient rainfall and nutrients, Water treatment (W) - with $3 \mathrm{~L}$ of water applied to each plant separately three times a week from June to August in Finland, and in Kentucky twice per week at $3.8 \mathrm{~L}$ per plant at each watering from April to October using trickle emitters and an irrigation timer. In Finland, nutrient treatment $(\mathrm{N})$ was 1 dl of N-P-K-fertilizer (Nurmen Y2, Kemira KnowHow) (N-P-K/20-6-6) applied two times during the growing season for each plant. In Kentucky fertilization consisted of $50 \mathrm{~kg} / \mathrm{ha}$ of N/per application in form of urea. Water and nutrient treatments (WN) combined both water and nutrient applications. These experiments allowed us to compare the effects of water and nutrient treatments within the experiments in Finland and Kentucky. However, comparisons between the two experiments should be done with caution because the sites inevitably differ in terms of numerous abiotic and biotic factors.

In 2005, all the experimental plants were re-checked to verify their endophyte status. In July, we sampled a pseudostem from each plant for immunoblot assay detection using monoclonal antibodies specific to Epichlö (Phytoscreen Immunoplot Kit \#ENDO7973, Agrinostics, Watkinsville, GA, USA). In addition, at the end of the summer, three seeds from each plant were stained (Saha et al.
1988), and endophytic infections were checked by microscopic examination. All plants included in this analysis were infected with Epichloe $(N=40,38,40,34$ and $N=35,38,40,38$ for A, G, S, and KY31 origins in Finland and Kentucky experiments, respectively).

The phenological timing of the two experiments is difficult to compare, and therefore we decided to sample regrowth leaf biomass of the experimental plants. The samples were collected from spring regrowth and fall regrowth in Finland and Kentucky, respectively. We obtained samples from all the $152 \mathrm{E}+$ plants in the Finnish experiment in mid-June 2006. A handful of green growth was cut at the height of $5 \mathrm{~cm}$ from the ground, placed into a plastic bag, and transported immediately to a deep-freezer $\left(-80 \mathrm{C}^{\circ}\right)$. The samples were ground, and the ground plant material from Finland was sent to Kentucky for alkaloid analyses. In Kentucky, $151 \mathrm{E}+$ plants were sampled in early November 2006. The samples from both experiments were analyzed using the same protocol.

Alkaloid Analyses Pyrrolizidine alkaloids [ $N$-acetylloline (NAL), $N$-formylloline (NFL), and $N$-acetylnorloline (NANL)] were extracted from powdered plant material with ethanol:methylene chloride $(4: 1, v / v)$ containing the internal standard quinoline and sodium bicarbonate following protocol of Blankenship et al. (2001). Individual alkaloids were resolved and quantified by gas chromatography equipped with FID detector. Chromatographic conditions were $15 \mathrm{~m} \times 0.53 \mathrm{~mm}$ DB5 column with initial oven temperature of $70{ }^{\circ} \mathrm{C}$ increased to $160{ }^{\circ} \mathrm{C}$ at $45 \mathrm{~min}^{-1}$, held for $5 \mathrm{~min}$, and increased to $290{ }^{\circ} \mathrm{C}$ at $45 \mathrm{~min}^{-1}$ and held for $7 \mathrm{~min}$.

Ergovaline, ergovalinine, and lysergic acid were measured by a modification of the procedure of Yates and Powell (1988). The HPLC was equipped with a fluorescence detector with excitation at $310 \mathrm{~nm}$ and measurement at $420 \mathrm{~nm}$. Separation was on an Alltech Alltima C18 $150 \times 4.6 \mathrm{~mm}$ column with $3 \mu$ particle size. Elution solutions were (A) $75 \mathrm{mM}$ ammonium acetate in water:acetonitrile $(3: 1, v / \mathrm{v})$ and $(\mathrm{B})$ acetonitrile. Elution gradient was 95:5 (A:B) for $1 \mathrm{~min}$; linear change to $60: 40(\mathrm{~A}: \mathrm{B})$ during the next $15 \mathrm{~min}$ and maintained for $5 \mathrm{~min}$; changed to $0: 100(\mathrm{~A}: \mathrm{B})$ during the next $1.5 \mathrm{~min}$ and maintained for $5 \mathrm{~min}$; changed to $100: 0(\mathrm{~A}: \mathrm{B})$ during the next $1 \mathrm{~min}$ and maintained for $6 \mathrm{~min}$ before returning to $95: 5$.

Statistical Analyses Statistical analyses were performed using R 2.15.2 statistical software (R Core Team 2012) by applying linear mixed models (Pinheiro et al. 2013). The experiments conducted in Finland and Kentucky were analyzed separately because the sites inevitably differ in terms of numerous abiotic and biotic factors.

Total ergot alkaloids and lysergic acids were used as the final response variables, as results based on individual compounds did not differ from models based on their sums. Lolines were analyzed as sums of $N$-acetylloline (NAL), $N$ - 
formylloline (NFL), and $N$-acetylnorloline (NANL). Normality of the residuals was gained after transformation as suggested by the Box-Cox analysis. All ergot alkaloids were $\log$ transformed $(\lambda=0)$, and to take into account zero values, one was first added to each compound before transformation. Lysergic acids were square root transformed $(\lambda=0.5)$. There was no need for transformation in lolines.

The statistical model for alkaloids included the fixed factors fertilization $(\mathrm{N})$ and water treatment $(\mathrm{W})$ treatments (included in models as, "N", nitrogen and nitrogen + water combined, "W", control and water treatment combined, and interaction, " $\mathrm{N} * \mathrm{~W}$ " between $\mathrm{N}$ and $\mathrm{W}$ ), plant origin (KY31, A, G, $\mathrm{S}$ ) and interactions between treatments and origin. Block was used as a random factor in all models. Association between different compounds within treatments $(\mathrm{N}$ and $\mathrm{W})$ and origins were analyzed in separate linear mixed models (i.e., comparison of ergot totals vs. loline totals in nitrogen and control treatments for each origin).

The full model with treatments, origins, and their interactions was fitted, and the non-significant factors were removed. Out of these models, we constructed the final model by including all factors that were significant at least in one of the experiments. This model is shown for experiments conducted in each site. Interaction plots were used in illustrating the significant interactions between the factors left in the models.

\section{Results}

All the 303 examined endophyte-infected tall fescue plants (152 from Finland and 151 from Kentucky) contained detectable amounts of ergot alkaloids and lolines. However, two S origin plants grown in Kentucky and one S and one KY31 origin plant grown in Finland did not produce lysergic acid.

Ergot Alkaloids Endophyte-infected tall fescue plants produced ca. $50 \%$ more total ergot alkaloids in Finland compared to the plants with same origin and treatments that were grown in Kentucky (Fig. 1). Total ergot alkaloid concentrations were similar compared to ergovaline and ergovalinine concentrations in the two experiments, all origins and treatments.

KY31 plants produced equivalent amounts of total ergot alkaloids in common garden experiments at both locations at the time of the sampling $(t=0.25, d f=69, P=0.80)$, while the wild origin plants produced more ergot alkaloids in Finland $(t=6.0, d f=211, P<0.001)$. In Finland, the ergot alkaloid production by A origin plants was four-fold greater, and by $\mathrm{S}$ or $\mathrm{G}$ origin plants was three-fold greater, than production by KY31 plants (Fig. 1). In the Kentucky experiment, the wild origin plants $(S, G, A)$ produced twice as much ergot alkaloids as the KY31 plants (Fig. 1).

Nutrition treatment tended to increase the amount of ergot alkaloids in Finland, but not in Kentucky (Table 1). Addition of nutrients was especially effective on A origin plants, which produced more than twice as much ergot alkaloids in nutrient $(\mathrm{N})$ and combined nutrient and water $(\mathrm{WN})$ treatments compared to control (C) and water (W) treatments in Finland (Fig. 2). Overall ergot alkaloid levels were lowest in the KY31 origin plants both in Finland and in Kentucky. Thus, KY31 expressed the lowest plasticity in response to nutrient and water treatments. Of the wild origin plants, A plants showed the highest plasticity followed by $\mathrm{G}$ and $\mathrm{S}$ origin plants (Fig 2., Table 1).

Lysergic Acid The total amount of lysergic acid, a precursor for a wide range of ergot alkaloids, was $60 \%$ higher in tall fescue plants grown in Kentucky compared to those grown in Finland.

In Finland, treatments and plant origin affected lysergic acid concentrations, but the fit of the model is poor ( $\log$ likelihood =33.4). In the Kentucky experiment, lysergic acid concentrations were significantly lower in KY31 plants compared to wild origin (A, G, S) plants (Table 2, model log likelihood $=-43.1$ ). Lysergic acid concentrations tended to be lower for water-treated plants.

Loline Alkaloids The amount of total lolines was $17 \%$ lower in plants grown in Finland compared to plants grown in Kentucky. In Finland, neither nutrients nor water application affected loline alkaloid concentrations (Fig. 2). In the Kentucky experiment, overall total loline concentrations $(N$ acetylnorloline, $N$-formyloline, $N$-acetyloline) of different plant origins were affected in different ways by different treatments causing high level interaction between the predictors (Fig. 1, Table 2).

Correlations Between Alkaloids In both the Finnish and the Kentucky experiments, different components within the three chemical groups, ergot alkaloids, lysergic acids, and lolines, showed high positive correlations (the lowest correlation in Finland was $r=0.67$ and in Kentucky $r=0.87)$ when all the treatments were included in the analysis. This indicates that e.g., a plant that produces high concentrations of ergot alkaloids also produces high concentrations of lysergic acid and lolines. Correlations between means of the three groups were higher in plants grown in Kentucky (correlations between 0.53 and 0.65 ) compared to those grown in Finland (correlations between 0.23 and 0.31). All these correlations were statistically significant. Correlations among individual chemicals were also higher in Kentucky plants (range $r=0.45$ to 0.67 ) compared to Finland plants (range $r=0.08$ to 0.45 ). 
Finland
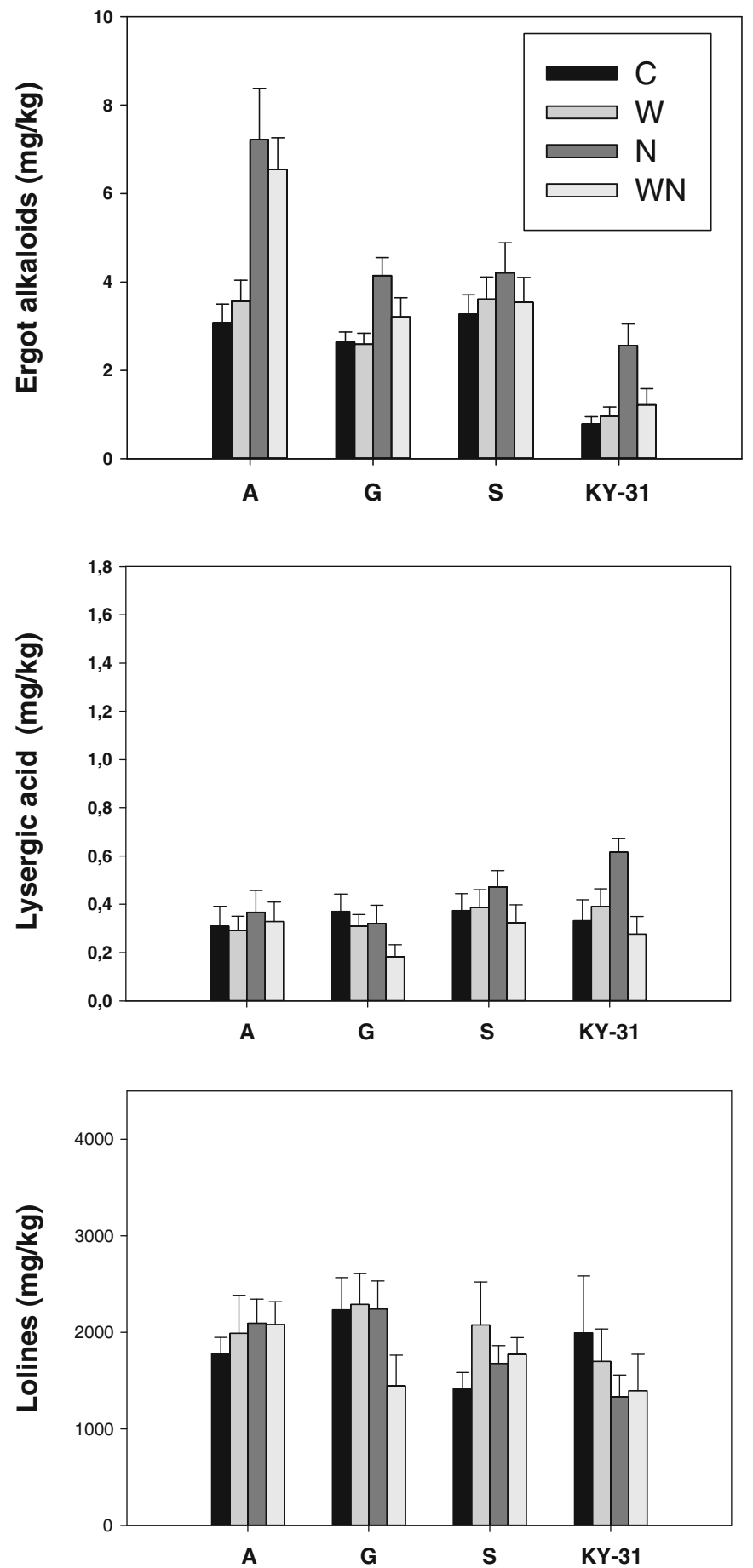

Fig. 1 Total ergot alkaloid, lysergic acid and loline contents of endophyte-infected tall fescue plants from three wild populations and one cultivar ( $A$ Åland island, $G$ Gotland island, $S$ mainland Sweden, $K Y-31$ cultivar 'Kentucky-31') grown in common garden in Finland

\section{Discussion}

In contrast to our prediction that KY31 should produce more ergot alkaloids than its wild population counterparts, KY31
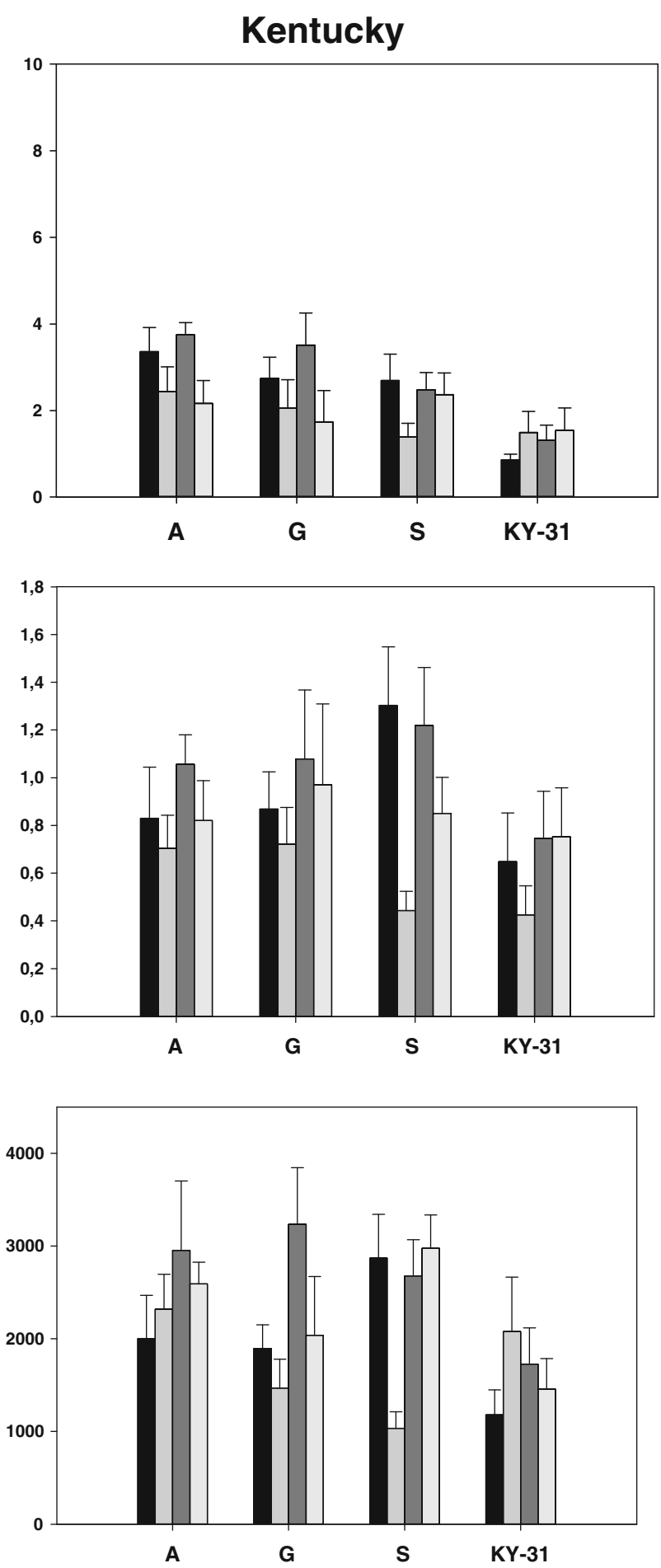

and Kentucky. The plants received either water $(W)$, nutrient $(N)$ or combined water and nutrient treatments $(W N)$ while control plants $(C)$ were left without extra water and nutrients (means \pm SE)

endophyte-infected plants produced 2-4 times lower ergot alkaloid concentrations compared to plants from wild European populations when the plants were grown in the same environmental conditions. The lower ergot alkaloid 
Table 1 Linear mixed models for total ergot alkaloids in tall fescue plants. The grasses from the wild origins (Orig) Gotland (G) and Sweden (S) and cultivar 'Kentucky-31' (KY31) were compared with wild origin Åland $(A)$ in water $(W)$ and nutrition $(N)$ treatment (Treat) plots. Results for the same model are shown for plants grown in Finland or Kentucky with all main factors and those interactions that were statistically significant in either of the experiments. Model estimates are standard errors (S.E.), degrees of freedom $(d f)$, and $t$-tests $(t)$ with $P$-values $(P) * * *<0.001, * *<0.01, *<0.05,0<0.1$

\begin{tabular}{|c|c|c|c|c|c|c|c|c|c|c|c|c|}
\hline & \multicolumn{2}{|c|}{ FINLAND } & \multirow[b]{2}{*}{$d f$} & \multirow[b]{2}{*}{$t$} & \multirow[b]{2}{*}{$P$} & & \multicolumn{2}{|c|}{ KENTUCKY } & \multirow[b]{2}{*}{$d f$} & \multirow[b]{2}{*}{$t$} & \multirow[b]{2}{*}{$P$} & \\
\hline & Value & S.E. & & & & & Value & S.E. & & & & \\
\hline Intercept & 1.980 & 0.104 & 103 & 19.04 & 0.001 & $* * *$ & 2.065 & 0.130 & 100 & 15.85 & 0.001 & $* * *$ \\
\hline Treat N & 0.839 & 0.130 & 36 & 6.45 & 0.001 & $* * *$ & 0.095 & 0.172 & 36 & 0.55 & 0.584 & \\
\hline Treat W & 0.144 & 0.130 & 36 & 1.11 & 0.276 & & -0.286 & 0.165 & 36 & -1.74 & 0.091 & o \\
\hline $\mathrm{W}^{*} \mathrm{~N}$ & -0.262 & 0.123 & 36 & -2.13 & 0.040 & $*$ & -0.064 & 0.165 & 36 & -0.39 & 0.701 & \\
\hline Orig G & -0.092 & 0.139 & 103 & -0.66 & 0.509 & & -0.122 & 0.163 & 100 & -0.75 & 0.454 & \\
\hline Orig S & 0.046 & 0.139 & 103 & 0.33 & 0.741 & & -0.278 & 0.159 & 100 & -1.74 & 0.084 & o \\
\hline Orig KY31 & -0.606 & 0.144 & 103 & -4.20 & 0.001 & & -0.694 & 0.160 & 100 & -4.34 & 0.001 & $* * *$ \\
\hline $\mathrm{N}^{*} \mathrm{G}$ & -0.461 & 0.163 & 103 & -2.84 & 0.006 & $* *$ & -0.036 & 0.189 & 100 & -0.19 & 0.849 & \\
\hline $\mathrm{N}^{*} \mathrm{~S}$ & -0.619 & 0.160 & 103 & -3.86 & 0.001 & $* * *$ & 0.027 & 0.188 & 100 & 0.15 & 0.884 & \\
\hline N*KY31 & -0.423 & 0.169 & 103 & -2.50 & 0.014 & $*$ & 0.011 & 0.189 & 100 & 0.06 & 0.953 & \\
\hline $\mathrm{W}^{*} \mathrm{G}$ & -0.133 & 0.163 & 103 & -0.82 & 0.416 & & -0.035 & 0.189 & 100 & -0.18 & 0.855 & \\
\hline $\mathrm{W}^{*} \mathrm{~S}$ & -0.047 & 0.160 & 103 & -0.29 & 0.772 & & 0.151 & 0.188 & 100 & 0.8 & 0.423 & \\
\hline W*KY31 & -0.176 & 0.170 & 103 & -1.03 & 0.304 & & 0.429 & 0.189 & 100 & 2.26 & 0.026 & $*$ \\
\hline AIC & 177.01 & & & & & & 214.71 & & & & & \\
\hline loglikelihood & -73.50 & & & & & & -92.35 & & & & & \\
\hline
\end{tabular}

production by KY31 was evident regardless of the experimental site (Finland or Kentucky) and the various water and nutrient treatments. We can conclude thus that the most widely grown tall fescue cultivar in US has genetically relatively low ability to produce ergot alkaloids compared to wild tall fescue plants from Northern Europe. This implies that the success of endophyte-infected tall fescue KY31 in North America and other areas has not been due to unusually high ergot alkaloid production under high herbivore pressure. Rather, success of KY31 tall fescue must be based upon some other traits associated with the symbiotum. The original selection criteria of the tall fescue cultivar KY31 were most likely its excellent
Fig. 2 Model-based (Table 1) estimated means of treatments ( $C$ control, $W$ water treatment, $N$ nutrient treatment, $W N$ water and nutrient treatment) for the endophyte-infected tall fescue plants from three wild populations and one cultivar $(A$ Åland island, $G$ Gotland island, $S$ mainland Sweden, $K Y$-31 cultivar 'Kentucky-31') for total ergot alkaloids and lolines in plants grown in Finland or Kentucky. Note that separate models were used for Finland and Kentucky
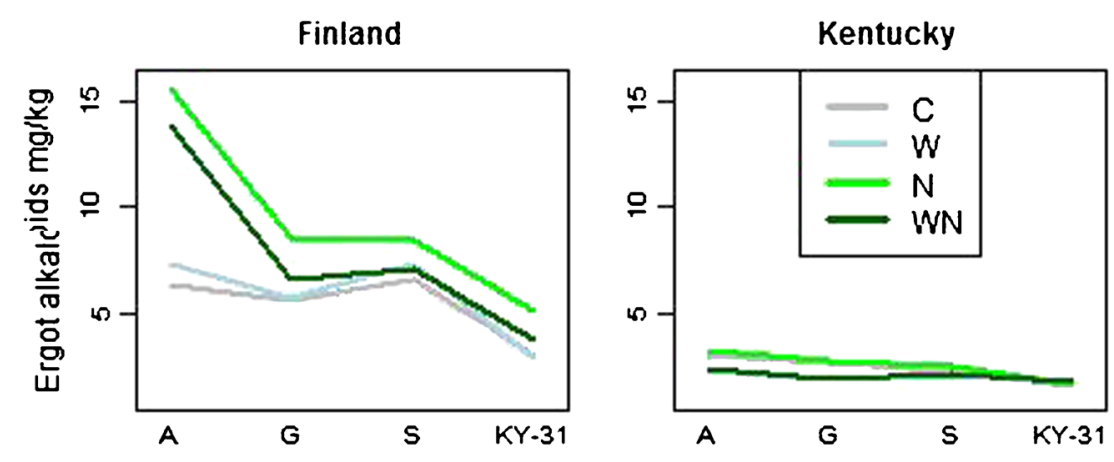

Finland

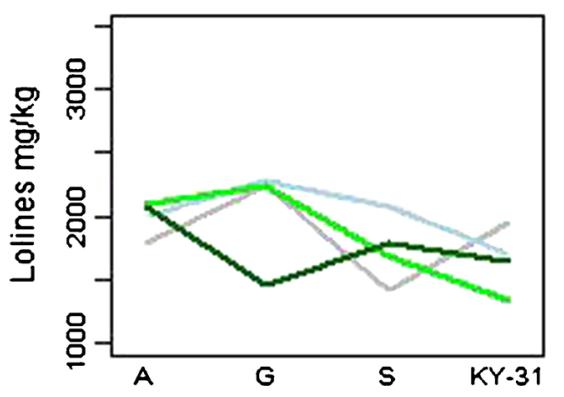

Kentucky

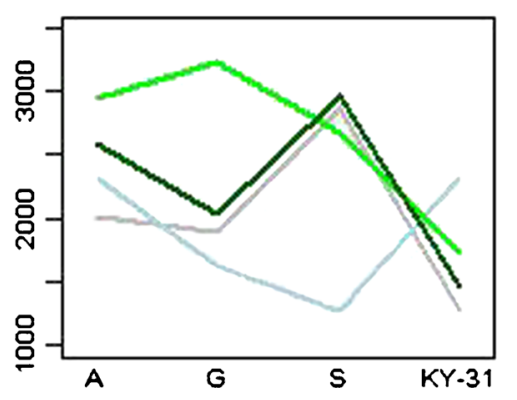


Table 2 Linear mixed models for total lysergic acids and lolines in tall fescue plants grown in Kentucky. The grasses from the wild origins (Orig) Gotland $(G)$ and Sweden $(S)$ and cultivar 'Kentucky-31' (KY31) were compared with wild origin Åland $(A)$ in water $(W)$ and nutrition $(N)$ treatment (Treat) plots. Results are shown for with all main factors and those interactions that were statistically significant. Model estimates are standard errors $(S . E$.), degrees of freedom $(d f)$, and $t$-tests $(t)$ with $P$-values $(P) * * *<0.001, * *<0.01, *<0.05,0<0.1$

\begin{tabular}{|c|c|c|c|c|c|c|}
\hline & LYSERGIC ACID & & & & & \\
\hline & Value & S.E. & $d f$ & $t$ & $P$ & \\
\hline Intercept & 0.960 & 0.067 & 106 & 14.355 & 0.001 & $* * *$ \\
\hline Treat W & -0.117 & 0.059 & 37 & -1.967 & 0.057 & o \\
\hline Treat N & 0.084 & 0.059 & 37 & 1.427 & 0.162 & \\
\hline Orig G & 0.005 & 0.067 & 106 & 0.073 & 0.941 & \\
\hline Orig $\mathrm{S}$ & 0.051 & 0.067 & 106 & 0.762 & 0.448 & \\
\hline Orig KY31 & -0.142 & 0.067 & 106 & -2.106 & 0.038 & $*$ \\
\hline AIC & 102.17 & & & & & \\
\hline \multirow[t]{3}{*}{ loglikelihood } & -43.09 & & & & & \\
\hline & LOLINES & & & & & \\
\hline & Value & S.E. & $d f$ & $t$ & $P$ & \\
\hline Intercept & 42.354 & 4.426 & 94 & 9.569 & 0.001 & $* * *$ \\
\hline Treat W & 11.330 & 6.963 & 36 & 1.627 & 0.112 & \\
\hline Treat $\mathrm{N}$ & 4.341 & 6.109 & 36 & 0.711 & 0.482 & \\
\hline $\mathrm{W}^{*} \mathrm{~N}$ & -7.556 & 9.161 & 36 & -0.825 & 0.415 & \\
\hline Orig G & 0.114 & 5.808 & 94 & 0.019 & 0.984 & \\
\hline Orig $\mathrm{S}$ & 9.512 & 5.641 & 94 & 1.686 & 0.095 & o \\
\hline Orig KY31 & -8.499 & 5.807 & 94 & -1.463 & 0.147 & \\
\hline $\mathrm{N}^{*} \mathrm{G}$ & -0.066 & 8.652 & 94 & -0.008 & 0.994 & \\
\hline $\mathrm{N}^{*} \mathrm{~S}$ & -13.004 & 8.541 & 94 & -1.523 & 0.131 & \\
\hline $\mathrm{N} * \mathrm{KY} 31$ & -4.916 & 8.652 & 94 & -0.568 & 0.571 & \\
\hline $\mathrm{W}^{*} \mathrm{G}$ & -7.875 & 8.098 & 94 & -0.972 & 0.333 & \\
\hline $\mathrm{W}^{*} \mathrm{~S}$ & -20.203 & 8.125 & 94 & -2.486 & 0.015 & $*$ \\
\hline $\mathrm{W}^{*} \mathrm{KY} 31$ & 8.132 & 8.420 & 94 & 0.966 & 0.337 & \\
\hline $\mathrm{N}^{*} \mathrm{~W}^{*} \mathrm{G}$ & -1.509 & 11.770 & 94 & -0.128 & 0.898 & \\
\hline $\mathrm{N}^{*} \mathrm{~W} * \mathrm{~S}$ & 26.624 & 11.709 & 94 & 2.273 & 0.025 & $*$ \\
\hline $\mathrm{N}^{*} \mathrm{~W}^{*} \mathrm{KY} 31$ & -8.947 & 11.916 & 94 & -0.751 & 0.455 & \\
\hline AIC & 1109.56 & & & & & \\
\hline loglikelihood & -536.78 & & & & & \\
\hline
\end{tabular}

agronomic attributes under drought, poor soils, and intense grazing (Saikkonen et al. 1998, 2004; Young et al. 2014).

Comparing results from intercontinental reciprocal transplantation experiment is challenging because uncontrolled abiotic and biotic factors inevitably differ between continents. For example, differences in soil types, timing and length of growing season, seasonal changes in weather conditions and day length are likely to affect alkaloid concentrations in the endophyte-grass symbiotum. However, tall fescue and particularly its cultivar KY31 is a unique baseline model for our study. Chemotypic diversity of tall fescue is well documented in the US (Siegel and Bush 1996), including ample evidence of seasonal changes in alkaloid production across years
(McCulley et al. 2014; Repussard et al. 2014). Thus, deviations from norms can be distinguished and linked to the explanatory or experimental factors.

For example, our results demonstrate clearly that wild grasses produced high amounts of ergot alkaloids in both study sites, whereas ergot alkaloid production of KY31 remained relatively low. In their five year field study, McCulley et al. (2014) observed total ergot alkaloid concentrations range between $0.4-1.9 \mathrm{mg} / \mathrm{kg}$ in KY31 tall fescue cultivar. This is in accordance with ergot alkaloid production by KY31 when grown in Finland or Kentucky (0.9-1.1 mg/ $\mathrm{kg}$ ) in the present study. However, the wild origin plants produced 3-5 and 2-3 times higher amounts of ergot alkaloids in Finland and in Kentucky, respectively. In addition, all ergovaline concentrations in our samples substantially exceeded the toxicity threshold value $(0.4 \mathrm{mg} / \mathrm{kg})$ known for cattle (Repussard et al. 2014). Thus, our results provide solid evidence for the potential of infected wild tall fescue genotypes to produce high levels of alkaloids with possible injurious effects on animal husbandry compared to KY31.

In contrast to recent experimental evidence by McCulley et al. (2014) that warming markedly increases concentrations of ergot alkaloids in tall fescue, our study found that levels of ergot alkaloids were higher in Finland than in the US where growing seasons are slightly warmer. This suggests that temperature alone fails to explain the alkaloid concentrations in endophyte-infected fescue. Higher concentrations of lysergic acid in plants growing in Kentucky suggest that the plants had high potential for ergot alkaloid production because lysergic acid is a precursor of ergot alkaloids (Schardl et al. 2013). Interestingly, in Finland the lysergic acid concentrations in plants with different origins were the same, while ergot alkaloid concentrations were higher in wild origin plants compared to KY31. This indicates that plant genotype $\mathrm{x}$ environment-interaction may play a significant role in the ergot alkaloid pathway.

McCulley et al. (2014) suggested that alkaloid production of lolines is boosted by combined effects of higher temperature and precipitation. Our results support this idea - concentrations of lolines were higher in plants grown in Kentucky. However, S origin plants produced low concentrations of lolines when they were treated with water, but high concentrations of lolines with the other treatments, consistent with the possible genotype $\mathrm{x}$ environment interaction in loline production in tall fescue plants.

As a testable hypothesis for future studies, we suggest that alkaloid production in certain grass-fungal genotype combinations is affected by combined effects of nutrient availability in soils, temperature, precipitation, and day length, which determine the energy available for photosynthesis. For example, shorter growing season but longer day length during the growing season in Finland, due to higher latitudes (Saikkonen et al. 2012), may promote photosynthesis and, accordingly, carbon resources in a plant. Alkaloids are nitrogen-based compounds 
and it has been suggested that harboring the systemic endophyte is costly to the plant when nutrients are the limiting factor in the soil (Ahlholm et al. 2002; Lehtonen et al. 2005; Saikkonen et al. 2006). Highly competitive fungal genotypes may reap benefits of photosynthate surplus in plants growing in long day conditions, but alkaloid production of fungus can be limited by nitrogen availability in soils. Thus, certain fungal genotypes may accumulate high amount of mycelia in the host plant but produce higher amount of alkaloids only when fertilized. Well replicated experimental studies with endophyte-plant genotypegenotype combinations coupled with quantifying mycelial biomass and alkaloid production in plants growing in differently fertilized soils are necessary to test this hypothesis. These results could be applied into grass breeding programs aiming to develop cultivars for different environments and purposes (Gundel et al. 2013; Saikkonen et al. 2015).

Open Access This article is distributed under the terms of the Creative Commons Attribution 4.0 International License (http:// creativecommons.org/licenses/by/4.0/), which permits unrestricted use, distribution, and reproduction in any medium, provided you give appropriate credit to the original author(s) and the source, provide a link to the Creative Commons license, and indicate if changes were made.

\section{References}

Ahlholm J, Helander M, Lehtimäki S, Wäli P, Saikkonen K (2002) Vertically transmitted endophytes: effects of environmental conditions. Oikos 99:173-183

Arechavalenta M, Bacon CW, Plattner RD, Hoveland CS, Radcliffe DE (1992) Accumulation of ergopeptide alkaloids in symbiotic tall fescue grown under deficits of soil water and nitrogen fertilizer. Appl Environ Microbiol 58:857-861

Bacon CW (1995) Toxic endophyte -infected tall fescue and range grasses: historic perspectives. J Anim Sci 73:861-870

Belesky DP, Stringer WC, Plattner RD (1989) Influence of endophyte and water regime upon tall fescue accessions. II. Pyrrolizine and ergopeptine alkaloids. Ann Bot 64:343-349

Blankenship JD, Spiering MJ, Wilkinson HH, Fannin FF, Bush LP, Schardl CL (2001) Production of loline alkaloids by the grass endophyte, Neotyphodium uncinatum, in defined media. Phytochemistry $58: 395-401$

Clay K, Holah J (1999) Fungal endophyte symbiosis and plant diversity in successional fields. Science 285:1742-1744

Dyer MI, Acra MA, Wang GM, Coleman DC, Freckman DW, McNaughton SJ, Strain BR (1991) Source-sink carbon relations in two Panicum coloratum ecotypes in response to herbivory. Ecology 72:1472-1483

Foote AP, Kristensen NB, Klotz JL, Kim H, Koontz AF, McLeod KR, Bush LP, Schrick FN, Harmon DL (2013) Ergot alkaloids from endophyte-infected tall fescue decrease reticuloruminal epithelial blood flow and volatile fatty acid absorption from the washed reticulorumen. J Anim Sci 91:5366-5378

Gundel PE, Pérez LI, Helander M, Saikkonen K (2013) Symbiotically modified organisms: nontoxic fungal endophytes in grasses. Trends Plant Sci 18:420-427
Hoveland CS (1993) Importance and economic significance of the Acremonium endophytes to performance of animals and grass plant. Agric Ecosyst Environ 44:3-12

Huitu O, Forbes K, Helander M, Julkunen-Tiitto R, Lambin X, Saikkonen K, Stuart P, Sulkama S, Hartley SE (2014) Silicon, endophytes and secondary metabolites as grass defenses against mammalian herbivores. Front Plant Sci 5:e478. doi:10.3389/fpls.2014.00478

Karban R, Baldwin IT (2007) Induced responses to herbivory. University of Chicago Press, Chicago

Lehtonen P, Helander M, Saikkonen K (2005) Are endophyte-mediated effects on herbivores conditional on soil nutrients? Oecologia 142: $38-45$

Leuchtmann A, Bacon CW, Schardl CL, White JF, Tadych M (2014) Nomenclatural realignment of Neotyphodium species with genus Epichloë. Mycologia 106:202-215

Malinowski DP, Belesky DP (2000) Adaptations of endophyte-infected cool-season grasses to environmental stresses: mechanisms of drought and mineral stress tolerance. Crop Sci 40:923-940

McCulley R, Bush LP, Carlisle AE, Ji H, Nelson JA (2014) Warming reduces tall fescue abundance but stimulates toxic alkaloid concentrations in transition zone pastures of the U.S. Front Chem 2:e88. doi:10.3389/chem.2014.00088

Pinheiro J, Bates D, DebRoy S, Sarkar D, the R Development Core Team (2013) Nlme: linear and nonlinear mixed effects models. R Package version $3: 1-108$

R Core Team (2012). R: A language and environment for statistical computing. $\mathrm{R}$ foundation for statistical computing, Vienna, Austria. ISBN 3-900051-07-0, URL http://www.R-project.org/

Repussard C, Zbib N, Tardieu D, Guerre P (2014) Endophyte infection of tall fescue and the impact of climatic factors on ergovaline concentrations in field crops cultivated in southern France. J Agric Food Chem 62:9609-9614

Rudall PJ, Prychid CJ, Gregory T (2014) Epidermal patterning and silica phytoliths in grasses: an evolutionary history. Bot Rev 80:59-71

Saari S, Helander M, Faeth SH, Saikkonen K (2010) The effects of endophytes on seed production and seed predation of tall fescue and meadow fescue. Microb Ecol 60:928-934

Saha DC, Jackson MA, Johonson-Cicalese JM (1988) A rapid staining method for detection of endophytic fungi in turf and forage grasses. Phytopathology 78:237-239

Saikkonen K (2000) Kentucky-31, far from home. Science 287:1887a

Saikkonen K, Faeth SH, Helander ML, Sullivan TJ (1998) Fungal endophytes: a continuum of interactions with host plants. Annu Rev Ecol Syst 29:319-343

Saikkonen K, Gundel PE, Helander M (2013) Chemical ecology mediated by fungal endophytes in grasses. J Chem Ecol 39:962-968

Saikkonen K, Lehtonen P, Helander M, Koricheva J, Faeth S (2006) Model systems in ecology: dissecting the grass-endophyte literature. Trends Plant Sci 11:428-433

Saikkonen K, Taulavuori K, Hyvönen T, Gundel PE, Hamilton CE, Vänninen I, Nissinen A, Helander M (2012) Climate changedriven species' range shifts filtered by photoperiodism. Nat Clim Chang 2:234-242

Saikkonen K, Wäli P, Helander M, Faeth SH (2004) Evolution of endophyte-plant symbioses. Trends Plant Sci 9:275-280

Saikkonen K, Young CA, Helander M, Schardl CL (2015) Endophytic Epichloë species and their grass hosts: from evolution to applications. Plant Mol Biol. doi:10.1007/s11103-015-0399-6

Schardl CL, Florea S, Pan J, Nagabhyru P, Bec S, Calie PJ (2013) The epichloae: alkaloid diversity and roles in symbiosis with grasses. Curr Opin Plant Biol 16:480-488

Siegel MR, Bush LP (1996) Defensive chemicals in grass-fungal endophyte associations. Recent Adv Phytochem 30:81-118

Vicari M, Bazely DR (1993) Do grasses fight back? The case for antiherbivore defences. Trends Ecol Evol 8:137-141 
Yates SG, Powell RG (1988) Analysis of ergopeptine alkaloids in endophyte-infected tall fescue. J Agric Food Chem 36: $337-340$

Young CA, Charlton ND, Takach JE, Swoboda GA, Trammell MA, Huhman DV, Hopkins AA (2014) Characterization of Epichlö coenophiala within the US: are all tall fescue endophytes created equal? Front Chem 2:e95. doi:10.3389/chem.2014.00095

Young CA, Hume DE, McCulley RL (2013) Fungal endophytes of tall fescue and perennial ryegrass: pasture friend or foe? J Anim Sci 91: $2379-2394$ 